\title{
HIEROSGAMOS, HIERODOULES, MAGNA MATER DAN \\ PROPAGANDA SEKS BEBAS DALAM NOVEL THE DA VINCI \\ CODE KARYA DAN BROWN
}

\author{
Reimundus Raymond Fatubun \\ Program Studi Pendidikan Bahasa Inggris \\ Universitas Cenderawasih \\ Jayapura, Papua, Indonesia \\ (rayf_ever@yahoo.com)
}

\begin{abstract}
ABSTRAK
Alusi-alusi tidak sekedar hadir dalam karya sastra tapi mempunyai signifikansi khusus dengan isi karya sastra. Dan Brown menggunakan banyak alusi dalam The Da Vinci Code. Alusi-alusinyaberasal dari abad-abad pra-Kristen, era awal Kristen sampai masa Renaissance dan Baroque dan dihubungkan dengan situasi dunia, terutama gereja. Alusi-alusi dari masa pra-Kristenhierosgamos, hieroedules dan Magna Mater mempropagandakan ritual seks. Dalam hubungan ini alusi-alusi itu mengarah pada tokoh Maria Magdalena. Hal-hal yang dikemukakan Brown tentang tokoh ini antara lain Jesus menikah dengan Maria Magdalena, bukan Petrus, yang diutus untuk mendirikan gereja.Dia harus disembah sebagai seorang dewi, persaudaraan rahasia the Priory of Sionmasih memujanya sebagai dewi dan mempertahankan praktek ini(Strobel \& Poole, 2006:25). Secara teoritik, tulisan ini menggunakanPiercian Semiotics, dan New Historicism (Greenblatt, 1980) yang mensejajarkan teks sastra dan non-sastra. Teks sastra dijelaskan sepenuhnya oleh teks non-sastra, tidak seperti Historicism.Tulisan ini menjelaskan alusi-alusi dan propaganda Dan Brown akan seks bebas.
\end{abstract}

Kata kunci: hierosgamos, hieroedules, Magna Mater, propaganda, the sacred feminine

\begin{abstract}
Allusionsare not merely present in literary works for no reasons but they have specific significance. Dan Brown uses a lot of allusions in The Da Vinci Codedating from pre-Christian, early Christian untill the RenaissanceandBaroqueeras. He relates them to world situations, especially the Church.Allusions from pre-Christianity are hierosgamos, hieroedulesandMagna Materwhich Brown uses to propogandize free sex.These allusions are related to Mary Magdalene. Issues connected with her in the novel are, among others, Jesus married her (pp. 242-250); Maria Magdalena, not Peter, whowastoestablish the Church (p. 254); she has to be worshipped as a goddess (p. 255); the secret brotherhood the Priory of Sionstill worships her as a goddessand maintains the practice (p. 255) (Strobel \& Poole, 2006:25). Theoretically, this paper uses
\end{abstract}


Piercian Semiotics, and New Historicism(Greenblatt, 1980s) which equates literary text with non-literary ones. Literary texts are fully explained with the help of non-literary ones, unlike Historicism.This paper is trying to explain allusions and Brown's propaganda for free sex.

Keywords: hierosgamos, hieroedules, Magna Mater, propaganda, the sacred feminine

\section{PENDAHULUAN}

"Allusion is a passing reference to historical or fictional character, places, or events, or to other works that the writer assumes the reader will recognize." (Morner and Rausch, 1991:5-6). Dengan demikian alusi bisa berupa informasi sejarah, tokoh fiksi, tempat, kejadian penting, mitologi, agama, karya sastra besar, seni, genre, dan seterusnya. Dalam sastra Inggris, misalnya, karya sastra yang lebih tua memakai banyak alusi dari peradaban Yunani dan Romawi; dalam karya-karya pujangga-pujangga Inggris dari abad Pertengahan sampai Renaissance, terdapat banyak alusi biblikal, walaupun alusi yang berasal dari zaman Yunani dan Romawi masih tetap ada. Para pujangga sekarang dapat menggunakan alusi-alusi yang berasal dari zaman purba sampai alusi-alusi abad ke dua puluh satu ini. Dan seterusnya. Dalam semiotika Piercian, dikenal istilah simbol, ikon, dan indeks yang semuanya bisa mempunyai referent pada tempat, zaman, atau kejadian lain. Yang perlu kritikus sastra kerjakan dalam menjelaskan sebuah karya sastra adalah memakai hermenetika atau proses signifikasi lain, istilah de Saussure, karena tidak semua pembaca telah memahami alusi-alusi itu.

\section{Riwayat Singkat Dan Brown}

Dan Brown adalah penulis Amerika yang telah menghasilkan beberapa novel. Yang laris dan menggoncang dunia, khususnya dunia Kristen, adalah The Da Vinci Code (2003) dan Angels and Demons (2000). Karya-karyanya yang lain adalah Digital Fortress (1998), Deception Point(2001) dan ada beberapa lagi yang lain. Dia tamatan Amherst College tahun 1986, lalu mengajar Bahasa Inggris di Phillips Exeter Academy. Dan Brown sebetulnya tidak punya latar belakang pendidikan dalam sejarah, seni, teologi, filsafat, kriptografi, atau pun arsitektur 
tapi dia berbicara dengan cukup meyakinkan dalam bidang-bidang ini. Untuk kepentingan sastra, pemakaian segala alusi dari bidang-bidang ini bukanlah hal yang baru atau mencengangkan. Tetapi kalau dia dengan meyakinkan mengatakan bahwa hal-hal ini semuanya adalah fakta, itu yang kurang bertanggung jawab. Dengan demikian poetic license-nya sebenarnya tidak berlaku. Kalaupun dia menggunakan poetic license-nya dia agak berlebihan dalam penggunaannya dan kurang bertanggungjawab.

\section{The Da Vinci Code}

Ini adalah sebuah novel oleh Dan Brown yang sangat kontraversial, bahkan sampai saat ini, dalam sejarah sastra dunia karena kebanyakan alusinya mengarah kepada ajaran agama Kristen, terutama gereja Katolik (bandingkan dengan novel The Satanic Verses karya Salman Rushdie, 1988). The Da Vinci Code (2003) telah menggoncang umat Kristiani sedunia. Salah satu isu yang diperbincangkan Brown adalah keseimbangan keilahian, divinity, antara unsur feminin dan unsur maskulin. Menurut Brown ada ketidakseimbangan kedua unsur ini pada tingkat divinity dalam peradaban umat manusia selama berabad-abad. Brown mau mengembalikan keseimbangan antara apa yang disebut the sacred feminine dan the sacred masculineini ini.The sacred feminine menurut Brown telah ditekan keberadaanya oleh gereja selama berabad-abad. Tetapi apakah ini pesan sponsor dari feminisme radikal, perlu kajian yang lebih mendalam. Novel Brown yang lain, Angels and Demons, yang juga sebuah best seller, yang tidak kalah daya goncangannya terhadap agama Kristen. The Da Vinci Code diterbitkan di New York oleh penerbit Dobleday tahun 2003.

Masalah yang akan dijelaskan dalam makalah ini adalah mengapa Dan Brown menggunakan alusi-alusi perkawinan dan kegiatan seks dari zaman pra Kristen sampai dengan zaman awal Kristen dan selanjutnya diproblematisasikan pada zaman sekarang. Untuk lebih fokus, pertanyaan-pertanyaan yang akan dijawab dalam makalah ini adalah: (1) apa itu hierosgamos dan mengapa Brown menggunakannya?;(2) apa itu hierosdules dan mengapa Brown menggunakannya?;(3) apa itu Magna Mater dan mengapa Brown 
menggunakannya?;dan (4) mengapa Brown mempropagandakan seks bebas dalam novelnya?

Tujuan makalah ini dengan demikian adalah (1) menerangkan secara singkat apa itu hierosgamos dan mengapa Brown menggunakannya; (2) menjelaskan secara singkat apa itu hierosdules dan mengapa Brown menggunakannya; (3) menjelaskan secara singkat apa itu Magna Mater(bd. ide mother of the maize dalam tradisi Peru misalnya) dan mengapa Brown menggunakannya; dan (4) menjelaskan secara singkat mengapa Brown mempropagandakan seks bebas dalam novelnya.

Dengan demikian isu-isu yang menjadi fokus antara lain ikon falus dan ikon yoni: $\Lambda$ dan $\mathrm{V}$, the pentagram, dan the Holy Grail yang mungkin mencoba menghidupkan kembali pemujaan para Magna Mater yang adalah inti dari isu the sacred feminine, hierosgamos, dan kegiatan seks kuil lainnya. Simbol-simbol yang lain akan disinggung juga secara sepintas dalam penjelasan isu-isu utama di atas.

Secara sastra pendekatan yang dipakai dalam menjelaskan isu-isu yang ada dalam makalah ini adalah New Historicism (diperkenalkan terutama oleh Stephen Greenblatt dari Universitas Harvard, 1980an). New Historicism menekankan foregrounding dari alusi-alusi sejarah dalam menjelaskan karya sastra, tidak seperti Historicism mula-mula. Karena kebetulan New Historicism ini memfokuskan diri pada sastra zaman Renaissance, pemakaiannya dalam tulisan ini tepat sekali karena walaupun novel ini bukanlah berasal dari masa Renaissance, alusi-alusi yang dipakai Brown banyak yang alusi-alusi zaman Renaissance dan Baroque. Kalau dilihat dari kajian semiotika, dapat pula dipakai Piercian semiotics(dalam Richter, 1989:848) yang mengatakan bahwa sistem tanda itu ada tiga jenis umum: (1) iconic signs, dimana signifier-nya menyerupai hal yang di-signified; (2) indexes, dimana signifier-nya adalah indikator yang dapat dipercaya akan kehadiran the signified yang disebut thereferent; dan (3) true symbols, dimana hubungan antara the signifier dan hal yang signified benar-benar arbitrari dan mengikuti konvensi yang ada yang disepakati bersama oleh sebuah kelompok tertentu. Dengan kata lain tidak ada hubungan inheren antara bentuk dan konsep dari hal-hal yang menjadi simbol benar-benar. Sudah tentu pemakaian 
konsep Piercian semiotics dalam makalah ini adalah yang masih sangat sederhana. Dapat juga dikemukakan di sini bahwa bila kita berbicara tentang wacana maka dapat pula dihubungkan dengan hal-hal yang berpotensi dalam sebuah sign yang berasal dari alusi-alusi itu menjadi referent dari icon, index, atau symbol yang ada (bd.intertextuality, Allen, 2005). Dengan demikian cara kerjanya adalah icon ke referent, index ke referent, atau symbol ke referent. Sesudah itu New Historicism berperan menerangkan referent yang ada yang telah ditemukan dalam alusi-alusi yang dipakai dalam novel itu. Secara sederhana hubungan itu dapat dilihat sebagai berikut:Allusions (Semiotics, Pierce): \{Icons, Indeces, Pure Symbols $\}>$ Referents $>$ New Historicism(Greenblatt)

\section{PEMBAHASAN}

\section{Hierosgamos: $\Lambda \mathrm{V}$}

Dua ikon pertama adalah ikon utama dominan yang dipakai Brown untuk salah satu ide novelnya. Dua ikon yang lainnya (untuk ikon pentagram atau tetragram, lihat juga ide sigillum Salomonis atau scutum Davidis) sebenarnya bentuk lebih nyata dari dua ikon pertama itu karena dua ikon pertama adalah bentuk yang sangat sederhana dari ikon-ikon serupa yang sudah ditambah, dimodifikasi, atau diperluas. Dua ikon ini adalah dua bentuk sangat sederhana dari ikonphallic dan ikonyonic. Inilah dasar Brown mempropagandakan kegiatan seks. Ide mengagungkan kegiatan seks bebas dalam hubungannya dengan ritual keagamaan ada dalam berbagai bentuk dalam sejumlah tradisi sejak dulu kala.

KonsepHierosgamos terkait dengan sacred, temple, atau religious prostitution yang dilakukan dalam hubungannya dengan peribadatan dimana hierosgamos adalah representasi pernikahan ilahiah. Hal ini bisa saja dilakukan dalam hubungannya dengan ritus kesuburan tetapi para ahli menyangsikan kebenaran isu ini karena bukti yang kurang cukup dari zaman purba. Hierosgamos atau sering disebut juga hierosgamy ini sebetulnya adalah ritual perkawinan antara seorang dewa dan seorang dewi yang dilaksanakan oleh manusia mewakili dewa dan dewi itu. Di Timur Dekat di zaman purba, hierosgamos ini dilakukan oleh seorang raja Sumeria dengan seorang pendeta wanita tertinggi dari dewi Inanna, yaitu dewi cinta, kesuburan, dan peperangan Sumeria. 
Dalam mitologi Yunani contoh hierosgamos adalah perkawinan antara Zeus dan Hera. Perkawinan serupa ini juga sering dilakukan antara seorang dewa atau dewi dengan seorang manusia biasa yang menghasilkan manusia-manusia setengah dewa (demigods, demigoddesses) seperti Hercules dengan 12 labor-nya yang terkenal itu, Arjuna dengan panah dan busurnya, dll. Bahkan Kanjeng Nyi Roro Kidul juga ada yang menggangapnya sebagai seorang demigoddess.

The Great Rite dalam tradisi Wicca juga didasarkan atas ritual hierosgamos ini. Dalam the Great Rite, hierosgamos biasanya diperlihatkan secara simbolik dalam bentuk sebuah pisau belati yang dimasukkan ujungnya ke dalam sebuah piala (yang adalah alat minum). Kadang-kadang hierosgamos ini dilakukan secara nyata oleh Pendeta Kepala Pria dan Pendeta Kepala Wanita.

Ritual hierosgamos inilah yang dilakukan oleh kakek dari Sophie Nevue, tokoh utama wanita, dalam The Da Vince Code. Apa yang dilakukan oleh kakek dari Sophie Nevue ini, Sauniere, di the chateau itu tidak dimengerti oleh Sophie sendiri. Dia mengira kakeknya melakukan sesuatu yang memalukan mengingat usianya yang sudah lanjut. Tetapi sebenarnya apa yang dilakukan kakeknya adalah ritual seks hierosgamos. Kakeknya yang dalam keadaan telanjang dan seorang nenek yang juga dalam keadaan yang sama melakukan hubungan hierosgamos ini seperti yang digambarkan oleh Brown berikut ini:

On a low, ornate altar in the center of the circle lay a man. He was naked, positioned on his back, and wearing a black mask. Sophie instantly recognized his body and the birthmark on his shoulder. She almost cried out. Grand-pere! This image alone would have shocked Sophie beyond belief, and yet there was more.

Straddling her grandfather was a naked woman wearing a white mask, her luxuriant silver hair flowing out behind it. Her body was plump, far from perfect, and she was gyrating in rhythm to the chanting - making love to Sophie's grandfather (p.338)

Dalam kutipan di atas, Brown menggambarkan secara singkat tapi jelas bagaimana ritual hierosgamos dilaksanakan dimana yang prianya telanjang bulat dan menggunakan topeng hitam, sedangkan wanitanya juga telanjang bulat dan memakai topeng putih. Mereka berdua ada di atas sebuah altar yang dihiasi secara detail dan melakukan hubungan intim layaknya sepasang suami-istri. 


\section{Hieroedules: $\Lambda$ V}

Sebetulnya hierodules adalah seorang mantan budak yang dibebaskan dari perbudakan untuk 'didedikasikan' kepada satu dewa tertentu. Dalam hubungan ini istilah ini sebetulnya bermakna sacred sex yang kemudian menjadi sacred prostitution untuk kepentingan ritual itu dimana tidak ada bayaran seperti prostitusi lazimnya. Dalam bahasa Ibrani dikenal kata qedesha yang diterjemahkan menjadi prostitusi kuil.

Hierodules kemudian bermakna sebagai seorang budak atau prostitusi yang melakukan hubungan badan dengan seorang pendeta perempuan atau pendeta pria. Para Magna Mater disembah dengan jalan melakukan ritual seks ini. Dalam ritus tertentu di Babilonia, hierosgamos dilakukan oleh seorang pendeta wanita dari dewi Ishtar dan seorang budak, yang kemudian budak itu dibunuh. Dalam hierosgamos ini mereka yang melakukannya dipercayai memperoleh pengalaman religius yang mantap atau pemerolehan pengetahuan khusus lewat kegiatan ritus seks ini (bd.gnosticism).

Ada dua kata yang berbeda dalam Perjanjian Lama: zonah dankedeshah (atau qedesha). Kata yang pertama hanya bermakna seorang prostitusi biasa sedangkan kata yang kedua kedeshah berarti "consecrated" (bentuk feminin). Tapi ini terjadi dalam sejumlah pengikut agama Kanaan karena Alkitab menegaskan bahwa prostitusi kultus tidak ada dalam Judaisme, baik dalam bentuk zonah ataupun kedeshah atau kadesh. Demikian bunyinya dalam Det.23:17-18: "Tidak ada anak gadis Israel akan menjadi seorang kedeshah, juga tidak seorangpun dari anak

laki-laki

Israel

menjadi

seorang

kadesh."

\section{Magna Mater: $\Lambda$ V}

Sudah dikatakan dalam abstrak bahwa banyak hal dikemukakan oleh Brown tetapi untuk makalah ini hanya dijelaskan hal-hal yang berhubungan dengan isuisu berikut ini karena sangat berhubungan dengan isu ritual seks dalam novel itu: (1) Jesus menikah dengan Maria Magdalena (hal. 242-250); (2) Maria Magdalena, bukan Petrus, yang diutus untuk mendirikan gereja (hal. 254); (3) Maria Magdalena harus disembah sebagai seorang dewi (hal. 255); dan (4) ada sebuah persaudaraan rahasia yang disebut the Priory of Sion yang masih memuja Maria 
Magdalena sebagai dewi dan mencoba mempertahankan praktek ini agar tetap hidup (hal. 255) (Strobel \& Poole, 2006:25). Tapi hal yang sangat penting untuk dikemukakan di sini yang berhubungan dengan kehadiran Yesus dan Maria Magdalena adalah konsepMagna Mater (the Great Mother). Magna Mater mengingatkan orang akanritual pagan yang dilakukan di kuil-kuil yang telah dijelaskan di atas. Praktek ritual seks di kuil-kuil ini dikenal sebagai hierosgamos atau hierogamy yang artinya 'pernikahan kudus' yang dipercayai berasal dari peradaban mula-mula sekali umat manusia, atau juga dalam bentuk hierosdules.

Dalam psikilogi moderen ide ini juga ada, seperti yang dikemukakan oleh Carl Jung, psikoanalis dan psikolog Swiss yang terkenal itu yang mengemukakan bahwa '... Magna Mater merepresentasikan kebenaran objektif akan Alam dalam bentuk figur seorang wanita yang keibuan, seorang dewi, atau seorang pendeta perempuan, tapi kadang-kadang Magna Mater juga mengambil bentuk sebuah gereja di sebuah kota atau distrik (Cirlot 1971:132). Dalam Merriam Webster's Encyclopedia of Literature (1995:488) dikatakan bahwa Magna Mater adalah "Ibu Agung dari segala dewa-dewi di Yunani-Romawi, dan di Oriental kuno dia dikenal dengan sejumlah nama lokal. Nama Cybele mendominasi sastra YunaniRomawi dari sekitar abad ke lima Sebelum Masehi ke depan. Nama resminya dalam bahasa Romawi adalah Deum Magna Idaea ("Great Idaean Mother of the Gods"). Orang Yunani juga menganggap Magna Mater ini sebagai representasi dari dewi mereka sendiri yaitu dewi Rhea dan akhirnya menyamakan keduanya. Orang-orang Romawi juga mengidentifikasi Magna Mater dengan dewi-dewi mereka seperti dewi Ops, dewi Tellus, dan dewi Ceres. Penyembahan terhadap dewi-dewi ini adalah salah satu ritual terpenting dalam peradaban Romawi.

Amstrong dalam A History of God (1993) mengatakan bahwa para Magna Mater berkembang dari peradaban purba yang masih didominasi oleh pertanian. Amstrong melanjutkan dengan mengatakan bahwa Magna Materitu penting dan menduduki posisi tinggi selama berabad-abad. Magna Mater ini mempunyai fungsi kesuburan dan oleh sebab itu tidak boleh dikacaukan dengan Magna Mater yangadalah the Great Mother of the gods.

Di Sumeria purba, dewi kesuburan ini adalah Inana yang menurut Storm (2003) ada sebuah upacara khusus yang dilakukan dimana sang raja menjadi 
Dumuzi, suami dari Inana, dan ketua pendeta wanita menjadi Inana. Pasangan ini akan melaksanakan sebuah ritual perkawinan yang tujuannya adalah agar ada kesuburan dan kemakmuran (Clayton, 1990:106, lihat juga Storm 2003:42). Magna Mater arketipe ini ada juga dalam budaya-budaya besar lainnya. Di Babilonia dia disebut Ishtar, di Kanaan dia disebut Anat, dan dia disebut Isis di Mesir (Clayton, 1990:107). Isis memiliki dua ciri khusus yaitu dia memiliki kekuatan magis dan mempunyai hubungan khusus dengan takta Mesir yaitu dia sebagai ibu simbolik sang Firaun (bd. kedudukan Kanjeng Nyi Roro Kidul) dalam tradisi Jawa.

Cybele, dewi ibu atau dewi pertiwi Syria digambarkan sebagai ibu sekaligus kekasih dewa Atis (Clayton, 1990:63, lihat juga Storm, 2003:26, Weigel, 1973). Di Roma kuno ada Diana. Dia adalah dewi perburuan dan oleh sebab itu dia dikenal sebagai Diana Nemorensis (Diana dari hutan). Dapat kita temukan alusi penting kepada Diana ini dalam Alkitab di mana orang banyak berseru 'Great is Diana of the Ephesians' ketika menentang pengajaran Santo Paulus (Kis. 19,34).

Di Yunani Demeter dikenal sebagai dewi kesuburan. Dia disejajarkan dengan para Magna Mater dari daerah-daerah Timur Dekat tapi terutama dengan Isis (Armstrong, 1993, lihat juga Storm, 2003).

Brown menggunakan konsep Magna Mater yang adalah the Mother goddess, bukan yang Mother of the gods dalam novelnya. Mengapa konsep ini yang diambil? Sudah tentu Brown mengambilnya karena cara pemujaan untuk konsep ritual seks tadi. Jadi bagaimanakah mereka disembah? Inilah persembahan yang ingin dipropagandakan oleh Brown untuk dihidupkan kembali. Dalam novel itu dikatakan bahwa orgasme itu adalah perantara atau alat orang untuk dapat bertemu dengan Tuhan karena dipercayai bahwa inilah yang terjadi di masa lalu ketika paraMagna Mater ini disembah. Hal ini perlu dilakukan untuk menjaga keseimbangan dalam pemujaan para dewa dan dewi yaitu keseimbangan pemujaan antara unsur laki-laki dan unsur perempuan. Menurut Brown keseimbangan ini telah terganggu dengan datangnya agama Kristen. Demi keseimbangan pemujaan inilah dewa dan dewi disembah di masa lalu. Sekarang para dewi tidak disembah secara signifikan lagi karena Tuhan saja yang disembah yang sering kali identik dengan laki-laki. Inilah yang telah terjadi selama berabad- 
abad sampai sekarang ini. Kesimbangan antara pemujaan terhadap the sacred feminine dan the sacred masculine inilah yang harus dikembalikan menurut Brown.

Ruether, dalam Goddesses and the Divine Feminine (2005), mengatakan bahwa kekerasan yang terjadi di seluruh bumi sekarang ini adalah karena kekuatan patriarki terlampau kuat. Dia bahkan mengatakan bahwa untuk menyembuhkan dunia dari penyakitkekerasan ini, institusi-institusi patriarki yang mendominasi dunia sekarang ini harus dihancurkan. Dengan menjatuhkan kekuatan maskulinisme ini yang sudah berlangsung sekitar tiga ribu tahun inilah umat manusia dapat diselamatkan. Menurutnya kekuatan spiritual akan lebih dipentingkan dari pada kekuatan yang berisifat fisik dan ketika itu terjadi para wanita akan berkuasa lagi. Bahkan ada kaum feminist yang ingin agar pemujaan Isis, sang Magna Mater termasyur dari Mesir itu, agar disembah dan dipuja kembali seperti zamanpara Firaun dulu karena pemujaan terhadap Isis (gambar kiri atas) ini tersebar sampai kekaisaran Romawi di zaman kuno.

Secara sosiologis, sebetulnya Brown mengangkat isu pertarungan gender. Karena gender yang satu lebih berkuasa dan menindas gender yang lain, gender yang lain ini berusaha untuk bangkit dan menjatuhkan gender penguasa dan penindas ini.Sekarang pada umumnya dipercayai juga bahwa ritme bulan lebih dahulu dipakai sebagai pengukur waktu sebelum ritme matahari dipakai untuk tujuan yang sama. Oleh sebab itu gender feminin mengangap bahwa merekalah yang lebih dahulu berkuasa dan mempunyai pengaruh dalam peradaban manusia tetapi mengapa sekarang mereka seakan dijajah oleh gender maskulin ini. Perlu ada keseimbangan dalam hal gender ini. Bahkan ada yang mencoba menggalakkan anak-anak dididik untuk menjadi manusia yang androgini yaitu manusia yang seimbang unsur-unsur gender feminin dan maskulinnya.

The Da Vinci Code ditutup dengan pentingnya Maria Magdalena harus disembah sebagai dewi seperti Isis (gambar kiri) dan dengan demikian apa yang diidamkan Ruether di atas akan menjadi kenyataan. Dengan kata lain, Maria Magdalena harus disembah sebagai Magna Mater yang terpenting dalam sejarah 
umat manusia. The Da Vinci Code ditutup dengan tokoh utama, Robert Langdon, menyembah tulang belulang Maria Magdalena yang dipercayainya:

He was standing beneath the ancient Rose Line, surrounded by the work of masters. What better place for Sauniere to keep watch? Now at last, he sensed he understood the true meaning of the Grand Master's verse. Raising his eyes to heaven, he gazed upward through the glass to a glorious, star-filled night.

She rests at last beneath the starry skies.

Like the murmurs of spirits in the darkness, forgotten words echoed. The quest for the Holy Grail is the quest to kneel before the bones of Mary Magdalene. A journey to pray at the feet of the outcast one.

With a sudden upwelling of reverence, Robert Langdon fell to his knees.

For a moment, he thought he heard a woman's voice... the wisdom of the ages... whispering up from the chasms of the earth. (p. 489)

Dalam kutipan ini digambarkan oleh Brown bahwa pencarian the Holy Grail, Cawan Suci, yang sangat terkenal dalam peradaban Barat yang sudah berlangsung selama berabad-abad ini sebetulnya adalah pencarian untuk menemukan kembali Maria Magdalena. Menurut Brown dalam novel ini, Maria Magdalena telah dicampakkan dan dilupakan. Dan ini dilakukan oleh Gereja, demikianinterpretasi Brown.

Menurut Brown, Hierosgamos, the Sacred Marriage itu harus tetap dijaga agar keseimbangan tetap terjaga antarathe sacred masculineyang dilambangkan dalam diri Yesus dan the sacred feminineyang dilambangkan dalam diri Maria Magdalena (gambar kiri) yang diperlihatkan dalam dua ikon yaitu falus dan yoni. Dalam The Da Vinci Code, Langdon, tokoh utama pria dalam novel itu, mengatakan bahwa agama Kristen telah memusnahkan the sacred femininedari kuil-kuil di seluruh dunia.

Menurut Brown, penyatuan yang paling suci antara the sacred masculine dan the sacred feminine adalah perkawinan antara Jesus dan Maria Magdalena di awal zaman Kristen itu. Inilah hierosgamosyang paling masyur dalam sejarah umat manusia. Oleh sebab itulah Maria Magdalena harus dijadikan sebagai Magna Mater terpenting dalam sejarah umat manusia karena setelah Yesus tiada 
Maria Magdalenalah yang harus meneruskan tradisi hierosgamos itu.Seperti yang sudah dikemukakan sedikit di atas, persaudaraan rahasia, the Priory of Sion, menjaga betul praktek hierosgamos ini dengan pelaku hierosgamos yang termasyur itu yaitu perkawinan ilahiah Yesus dengan Maria Magdalena. Keluarga Jaques Sauniere dan cucunya Sophie Neveu Saint-Clair adalah keturunan dari Yesus dan Maria Magdalena yang masih ada menurut the Da Vinci Code. Ritual hierosgamos yang dilakukan oleh kakek dari Sophie Nevue adalah untuk meneruskan praktek perkawinan ilihiah antara Yesus dan Maria Magdalena itu tetapi belum dipahami oleh Sophie Neveu sendiri.

Sudah tentu Dan Brown berbicara sebagai seorang yang non-Katolik. Kemungkinan besar dia tidak mengerti posisi Bunda Maria dalam dogma gereja Katolik yang menempatkan posisi Bunda Maria sebagai Magna Mater(kalau dipinjam konsep ini) terbesar dan terpenting di alam semesta ini. Bunda Maria adalah Magna Mater tersuci dalam dogma Katolik karena dia tetap perawan walaupun telah mengandung Yesus. Untuk membicarakan posisi Bunda Maria sebagai Magna Mater ini perlu tulisan lain yang lebih komprehensif oleh orang yang lebih kompeten dalam dogma Katolik.

Kalau kita berbicara mengenai ritual hierosgamos, sebetulnya konsep itu juga ada dalam Gereja Katolik. Hanya saja dogma yang diajarkan oleh Gereja itu lebih bersifat spiritual dalam penyatuan Yesus dengan Gerejanya. Dengan kata lain, hierosgamos yang ada dalam dogma Katolik yaitu bahwa Yesus adalah pengantin prianya sedangkan Gereja adalah pengantin wanitanya. Oleh sebab itulah Magna Materyang ada dalam ajaran Gereja adalah Gereja itu sendiri seperti yang dikatakan oleh Carl Jung sebelumnya ketika ia memberi definisi tentang Magna Mater ini. Dalam ajaran Gereja, hierosgamos abadi di jagad raya ini adalah penyatuan Yesus dengan Gerejanya.

\section{Propaganda Dan Brown: Seks Bebas dan Materialisme}

Dalam novel ini telah kita lihat bahwa simbol-simbol yang mempropagandakan aktivitas seks sangat diagungkan seperti yang dilambangkan dengan simbol phallic dan yonic di atas. Kegiatan seks sangat diselebrasi tetapi tidak seperti yang diajarkan oleh agama Kristen selama lebih dari dua ribu tahun 
terakhir yang lebih mengarah ke kesucian tubuh yang membawa kesucian jiwa karena panahanan akan nafsu birahi akan membawa orang lebih menuju ke kesucian jiwa yang akan menyiapkan jiwa itu masuk surga.

Untuk menarik orang mengikuti pemujaan seperti yang dikemukakan Brown ini mudah sekali dilakukan. Generasi muda sudah tentu akan menjadi pengikut paling setia dan paling aktif. Kalau anak-anak muda disuruh untuk menyembah dewa dewi dalam bentuk kegiatan seks ini,hierosgamosdanhierodule yang adalah unsur terpenting dalam kegiatan ritual keagamaan, anak-anak muda dengan mudahnya akan mengikuti ajaran ini dan seks bebas akan merajalela di seluruh bumi. Secara singkat dalam novel dikatakan bahwa kalau seseorang mau bertemnu Tuhan, hal yang harus dilakukannya adalah mencapai orgasme. Anak muda diundang dengan mudah untuk bergabung dan pengikutnya akan segera melangit.

Magna Mater juga telah disinggung oleh Amstrong dalam A History of God (1993). Memang menurut penelitian arkeologi dan antropologi manusia memulai peradaban dengan menetap pada suatu tempat karena mereka mulai bercocok tanam dan mendomistikasi hewan menjadi hewan piaraan atau hewan untuk dipakai membantu petani di ladang untuk membajak tanah misalnya. Tanah yang digarap perlu sekali menjadi subur agar panen bisa melimpah. Pentingnya kesuburan ini membuat orang berpikir akan kekuatan supernatural untuk membantu mereka dalam tetap memberikan kesuburan pada tanah dan tanaman mereka. Hal inilah yang membuat manusia membuat ritual-ritual untuk memuja para entiti supernatural ini agar tetap memberikan kesuburan. Menurut arkeologi dan antropologi situasi ini dimulai sekitar tujuh ribu tahun yang lalu di masa Neolithic Revolution di Timur Tengah (Minns, 2003) dan berkembanglah dewidewi kesuburan yang kemudian menjadi para Magna Mater konsep yang disukai Brown ini. Minns mungkin sekali mengacu pada Amstrong. Dalam pemahaman akan kesuburan dalam bercocok tanam inilah, ada perasaan bahwa membuat sesuatu menjadi hidup dan subur adalah sesuatu yang sakral. Dan kalau manusia kurang berhasil menyuburkan tanahnya untuk menghasilkan panen melimpah diperlukan kekuatan magis atau supernatural. 
Para Magna Mater ini mendudduki posisi tinggi dan terhormat selama berabad-abad. Mereka dipuja dan disembah dalam berbagai nama tapi dengan fungsi yang serupa di seluruh dunia seperti yang telah disebutkan di atas. Di Indonesia kita mengenal dengan betul kata Ibu Pertiwi. Para dewi ini juga terkenal sebagai dewi bulan karena bulan dianggap sebagai simbol materi. Menurut Evola (dalam Cirlot, 1962:206) materi itu sama dengan bulan. Bulan juga mempunyai potensi akan kejahatan. Dengan demikian Magna Mater ini sebenarnya merepresentasi materialisme juga. Cisero juga menjelaskan kemunculan para Magna Mater ini yang berkaitan dengan bulan. Nama-nama Magna Mater yang lain adalah misalnya Ishtar, Hathor, Anaitis, dan Artemis.

Ketika masa kejayaan para Magna Mater ini menghilang, karakter feminin diberikan kepada bulan dan karakter maskulin diberikan kepada matahari. Di sinilah mulai munculnya ide hieros gamos yaitu perkawinan antar langit dan bumi yang dilakukan oleh representasi keduanya oleh para pendeta wanita dan pendeta pria di kuil-kuil para dewa-dewi ini.Krappe (dalam Cirlot, 1962:214-215), berkaitan dengan menurunnya kekuasaan matriarki ini, mengatakan bahwa

"When patriarchy superseded matriarchy, a feminine character came to be atrributed to the moon and a masculine to the sun. The hieros gamos, generally understood as the marriage of heaven and earth, may also be taken as the union of the sun and the moon."

Agak berbeda dengan beberapa budaya seperti Sumeria, Jepang, dan budaya-budaya Oceania, bulan adalah dewi, bukan dewa seperti beberapa budaya pengecualian di atas. Budaya-budaya yang masih melakukan perburuan hewan di hutan masih menurunkan praktek pemujaan terhadap bulan ini karena di zaman kuno pencahayaan bagi mereka satu-satunya hanyalah bulan. Oleh sebab itulah bulan dan wanita sering dihubungkan secara simbolik dalam praktek-praktek akult, sihir, emosi dan situasi yang berubah-ubah. Dengan kata lain dianggap bahwa bulan merepresentasikan materi.

Materialisme sangat dekat dengan Satanisme. Dalam dunia materialisme, matter atau benda menjadi hal yang sangat diagung-agung dalam hidup. Wilczynski (1984:347) mengatakan bahwa dalam filsafat, meterialisme adalah "salah satu dari dua arah berpikir yang mana materialisme mengganggap bahwa materi itu yang paling penting, ... semua yang imaterial itu dianggap tidak ada 
atau kelas dua yang berasal dari materi. Dengan kata lain, materialisme mengatakan dengan tegas bahwa hanya ada satu realitas - dunia materi." Stack (1998) seperti yang dikutip dalam (http://members.aol.com/ NeoNoetics/ Materialism.htm) mengatakan bahwa “... materialisme menyangkal keberadaan makluk-makluk roh ... . Karena materialisme ini menyangkal keberadaan maklukmakluk roh ... materialisme bersekutu dengan ateisme dan agnostisisme."

Materialisme sebetulnya sudah digalakkan sejak Firaun Akhenaten, putra Firaun Amenhotep III dari Mesir. Ia memusnahkan semua dewa dewi yang lain dan hanya menyembah dewa Aten saja yaitu matahari yang kita lihat setiap hari yang dalam bentuk materi ini. Peristiwa ini juga adalah kemunculan monoteisme secara intelektual dalam sejarah umat manusia. Dengan demikian ritual-ritual keagamaan direduksi dan dengan demikian spiritualisme menjadi terpinggirkan (walaupun dalam bentuk materi itu).

Monoteisme yang dibawa oleh Musa sudah tentu berbeda dengan monoteisme yang dipikirkan oleh Akhenaten ini. Monoteisme Musa lebih spiritual dalam arti sebenarnya sedangkan monoteisme Akhenaten lebih materialistis. Kehancuran yang dibuat oleh Akhenaten begitu dasyatnya sehingga orang Mesir menamai situasi kehancuran yang diperbuatnya ini sebagai Sethian Event. Seth sudah tentu adalah Setan (Balck, 2010:238).

Di Israel juga telah muncul materialisme ketika pemerintahan raja Solomon. Dialah yang memerintahkan arsitek Phunisia yang bernama Hiram Abiff untuk mendirikan King Solomon's temple yang terkenal itu. Pembangunan kuil megah ini sesuatu yang baru secara materi karena orang Israel masih merupakan bangsa yang mengembara waktu itu yang masih sangat mementingkan spiritualisme dalam arti yang sebenarnya.

Materi ini disimbolkan dalam Alkitab dengan 'perut' seperti yang ditemukan dalam Santo Paulus yang mengingatkan orang-orang Filipi yang "tuhannya adalah perutnya" (3:19) atau dia juga mengingatkan orang-orang Romawi dalam Roma 16:18, "karena mereka yang demikian itu tidak melayani Tuhan Yesus Kristus melainkan perut mereka." Santo Paulus mengingatkan orang-orang Kristen yang tidak berjuang "melawan daging dan darah,""... melawan kekuatan, melawan pemimpin-pemimpin kegelapan di dunia ini, 
melawan kejahatan spiritual ..." (Ef. 6:12). Dalam dunia yang demikian orang lebih "menyukai kegelapan daripada terang, karena perbuatan mereka jahat" (Yoh. 3:19; bd. 1 Yoh. 2:15-17). Apa yang dikatakan di sini adalah bahwa kalau orang memuja dewa dewi dengan cara hierosgamos (hierogamy) 'pernikahan kudus' atau juga dalam bentuk hierosdulesorang lebih memuja daging daripada roh.

\section{SIMPULAN}

Alusi adalah referensi atau pengacuan kepada hal-hal lain, apakah hal-hal lain itu berhubungan dengan sejarah, tokoh fiksi, tempat, atau karya-karya lain yang pujangga anggap pembaca punya pengetahuan akan hal-hal itu. Namun tidak semua orang mempunyai pengetahuan yang luas. Kebanyakan orang tidak mempunyai kemampuan untuk memiliki banyak alusi dalam pikirannya. Karyakarya sastra besar dunia seperti The Da Vinci Code dipenuhi dengan alusi-alusi yang bukan main banyak dan kompleks.

Oleh sebab itu karya sastra besar seperti The Da Vinci Code sangat perlu dijelaskan maksud pemakaian alusi-alusi di dalamnya agar khalayak ramai mengerti apa maksud pujangga menggunakan alusi-alusi itu. Pujangga sering kali berlindung di belakang poetic license-nya untuk tujuan tertentu. Kalau alusi-alusi dalam karya sastra besar tidak dijelaskan, bisa saja para pembaca mengira bahwa alusi-alusi yang ada dalam karya sastra itu yang diinterpretasikan oleh pujangga sendiri untuk kepentingan tujuan karya sastranya itu, adalah benar-benar sejarah, ajaran agama, atau ha-hal lain yang dianggap fakta dan diyakini atau dipertentangkan seperti yang terjadi pada The Da Vinci Code.

Dengan menggunakan Piercian Semioticsdan New Historicismtentang hubungan iconic signs, indeces, dan true symbolsdan referent-nya, sejumlah dari sekian alusi penting yang dipakai Brown yang menjadi fokus tulisan ini yaitu hierosgamos, hierosdules, magna mater yang semuanya berhubungan dengan the sacred masculine dan the sacred femininedan isu-isu lain yang terkait telah dijelaskan secara singkat. Alusi-alusi ini sangat berhubungan dan berpusat pada

ikon-ikon ini: $\mathbf{\Lambda} \mathbf{V}$. Namun dua ikon yang pertama adalah bentuk pakem dari bentuk-bentuk lain, yang dua diantaranya disertakan juga bersama-sama dua 
ikon bentuk pakem itu yaitu the pentagram yang merupakan penyatuan antara ikon $\mathbf{\Lambda}$ dan ikon $\mathbf{V}$ sedangkan the chalice ¿atau grailadalah bentuk lain dari $\mathbf{V}$. Sering kali orang juga dapat melihat penyatuan ikonphallicdanyonic itu, selain dalam bentuk pentagram, juga dalam bentuk penyatuan yang lain.

Secara singkat dapat dikatakan bahwa lewat ikon-ikon yang sangat spesifik ini dan narasi yang panjang lebar sang pujangga Dan Brown mau mempropagandakan kepada pembaca, terutama anak-anak muda, untuk mempraktekan kembali ritual Sacred Marriage ini karena itu adalah ritual terpenting dalam penyembahan terhadap para dewa dewi yang dipercayai Dan Brown. Dan itulah yang terjadi pada awal Kekristenan menurutnya. Gereja, menurut pendapat Brown, telah memusnahkan praktek ritual ini sejak berabadabad lalu. Begitu seseorang melakukan ritual ini dan mencapai orgasme, orang itu telah mencapai keberadaan dewa-dewi itu atau Tuhan. Itulah Hierosgamos.

\section{DAFTAR PUSTAKA}

Achen, Sven Tito. 1981. Symbols Around Us. Victoria: Van Nostrand Reinhold Company.

Amstrong, Karen. 2001. Holy War: The Crusades and Their Impact on Today's World. New York: Anchor Books.

Amstrong, Karen. 1993. The History of God: The History of God: The 4,000-Year Quest of Judaism, Christianity, and Islam. New York: Ballantine Books

Baldick, Chris. 1991. The Concise Oxford Dictionary of Literary Terms. New York: Oxford University Press.

Barry, Peter. 1995. Beginning Theory: An Introduction to Literary and Cultura Theory. Manchester: Manchester University Press.

Bell, Roslynne. 2007.Power and Piety: Augustan Imagery and the Cult of Magna Mater, Doctoral Dissertation. Canterbury: University of Canterbury. (http://digital-library.canterbury.ac.nz/data/collection3/etd/adtNZCU20070517.143204/01 front.pdf, diunduh2 November, 2008)

Berger, Helen A. 1999. A Community of Witches : Contemporary Neo-paganism and Witchcraft in the United States Studies in Comparative Religion. South Carolina: University of South Carolina Press.

Biedermann, Hans. 1992. Dictionary of Symbolism. New York: Penguin Books. Blackburn, S. 1996. Dictionary of Philosophy. Oxford: Oxford University Press. Brown, Dan. 2004. The Da Vinci Code. New York: Doubleday

Carey, Gary. (Ed). 1991. Mythology. Lincoln: Cliff Notes Inc.

Cirlot, J.E. 1962. A Dictionary of Symbols. London: Routledge\&Kegan Paul Ltd. Clayton, Peter. Great Figures of Mythology. New Jersey: Crescent Books.

Garlow, James L. \& Jones, Peter. 2004. Cracking the Da Vinci Code. Colorado Springs: Victor 
Graham, Allen. 2005. Intertextuality. New York: Routledge.

Greenblatt, Stephen. 2004. Will in the World. New York: W.W. Norton \& Company, Inc.

Haag, Michael \& Haag Veronica. 2004. The Rough Guide to The Da Vinci Code. London: Rough Guides Ltd.

McDowell, Josh. 2006. A Quest For Answers: The Da Vinci Code. Holiday: Green Key Books.

Minns, Peter (Producer and Director). 2003. In Search of Eden. (documentary). MMI Discovery Communication, Inc.

Olson, Carl E. \&Miesel, Sandra. 2004. The Da Vinci Hoax. San Francisco: Ignatius Press.

Ruether, Rosemary Radford. 2005. Goddesses and the Divine Feminine. Los Angeles: University of California Press

Shea, Mark \& Sri, Edward. 2006. The Da Vinci Deception. West Chester: Ascension Press.

Storm, Rachel. 2003. The Encyclopedia of Eastern Mythology. London: Lorenz Books.

Tresidder, Jack. 2011. 1001 Symbols. London: Watkins Publishing.

Veeser, H. Aram. 1994.The New Historicism. New York: Routledge.

Weigel, Jr., James. 1973. Mythology. Lincoln: Cliffs Notes Inc.

Welborn, Amy. 2004. De-coding Da Vinci. Huntington: Our Sunday Visitor, Inc.

Wilczynski, Josef. 1984. An Encyclopedic Dictionary of Marxism Socialism \& Communism. London: The Macmillan Press LTD.

Tanpa Nama. 1984. The Bible: God's Holy Word, New International Version. Colorado Springs: International Bible Society.

\section{Websites}

\section{Tentang Ideologi}

(George. J. Stack, Routledge Encyclopedia of Philosophy, 1998 cited in http://members.aol.com/NeoNoetics/Materialism.htm).http://en.wikipedia.org/wik i/TheisticSatanism (Online) diakses tgl 20 August 2012

\section{Tentang Para Dewa-Dewi dan Asosiasi Mereka}

Carlo Dolci, Italy, Mid-1640s (http://www.arthermitage.org/Carlo-Dolci/St-MaryMagdalene.html) (Online) Dewi Isis, http://www.landofpyramids.org/isis.htm, diaksestgl 14 Mei 2015.

\section{Tentang Hal-Hal Magis}

http://en.wikipedia.org/wiki/Pentagram (Online) diakses tgl 20 Agustus 2012 